\title{
Estudo sobre sombreamento em planta fotovoltaica localizada em zona urbana de Fortaleza-CE
}

\author{
Study on shading in photovoltaic plant located in urban \\ area of Fortaleza-CE
}

\author{
Estudio sobre sombra en planta fotovoltaica ubicada en \\ zona urbana de Fortaleza- CE
}

\section{Étude sur lıombrage dıune cellule photovoltaïque située dans la zone urbaine de Fortaleza-CE}

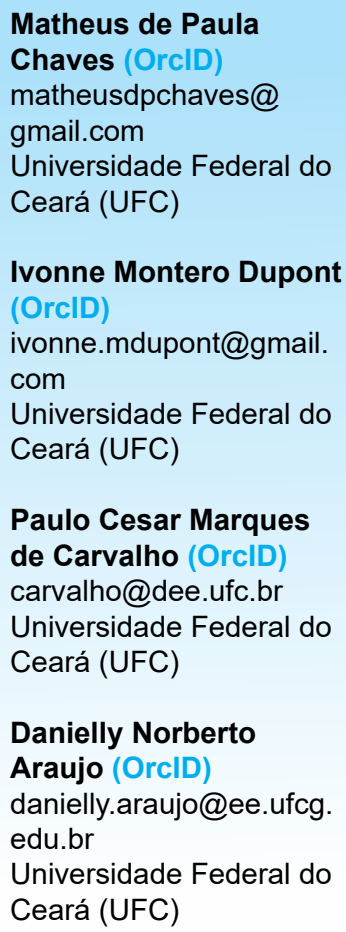

Ivonne Montero Dupont (OrcID)

ivonne.mdupont@gmail. com

Universidade Federal do Ceará (UFC)

Paulo Cesar Marques de Carvalho (OrclD) carvalho@dee.ufc.br Universidade Federal do Ceará (UFC)

Danielly Norberto Araujo (OrcID) danielly.araujo@ee.ufcg. edu.br Universidade Federal do Ceará (UFC)

\begin{abstract}
Resumo
Em decorrência do avanço da implementação de plantas fotovoltaicas (FV) localizadas em grandes centros, estudos são necessários para analisar os fatores que afetam essa geração de energia elétrica. No presente artigo, uma análise é realizada sobre o impacto do sombreamento em uma planta FV localizada em zona urbana e conectada à rede elétrica do Laboratório de Energias Alternativas (LEA) da UFC, campus Pici, Fortaleza-CE. Antes de cada experimento foi feita a limpeza dos módulos fotovoltaicos, de maneira a garantir maior confiabilidade ao estudo. Para a análise, foram gerados diferentes padrões de sombreamento, estáticos e dinâmicos, visando simular situações reais de não idealidades na planta. O sombreamento estático consiste na sombra projetada sobre os módulos que não varia sua posição ao longo do tempo; no sombreamento dinâmico, a sombra varia no decorrer do tempo. Para comparar as variáveis de desempenho da planta FV, foram escolhidos dias com médias de irradiância semelhantes durante o período dos experimentos. Calculou-se o fator de capacidade (FC) para os quatro experimentos analisados, divididos em duas situações de sombreamento estático e duas de sombreamento dinâmico. Como resultado, obteve-se uma redução do $\mathrm{FC}$ de 2,35\% e 1,17\% para o primeiro caso, e de $0,84 \%$ e 1,72\% para o segundo. As curvas de potência e irradiância foram observadas e verificou-se que, para baixas irradiâncias (inferiores a $500 \mathrm{~W} / \mathrm{m}^{2}$ ), o sombreamento não interferiu de modo significativo na potência gerada. A importância dos diodos by-pass e sua atuação para evitar que determinadas células sombreadas comportem-se como carga foi explicitada.
\end{abstract}

Palavras-chave: Planta fotovoltaica. Sombreamento. Perdas.

\begin{abstract}
Due to the advance of the implementation of Photovoltaic (PV) plants located in large centers, studies are needed to analyze the factors that affect this generation of electric energy. In this paper, an analysis is carried out on the impact of shading on a PV plant located in an urban area and connected to the electric grid of the Alternative Energy Laboratory (Laboratório de Energias Alternativas - LEA) of UFC, Pici campus, Fotaleza-CE. Before each experiment, the $\mathrm{PV}$ modules were cleaned in order to guarantee greater reliability in the study. For the analysis, different static and dynamic shading patterns were generated aiming to simulate real situations of non-idealities in the plant. Static shading consists of the shadow projected on the modules that does not vary its position over time; in the dynamic shading, the shadow varies over time. To compare the performance variables of the PV plant, days with similar irradiance averages were chosen during the period of the experiments. We calculated the Capacity Factor (FC) for the four experiments analyzed, divided into two situations of
\end{abstract}


static shading and two of dynamic shading. As a result, a reduction of the $\mathrm{CF}$ of $2.35 \%$ and $1.17 \%$ was obtained for the first case and $0.84 \%$ and $1.72 \%$ for the second. It observed the power and irradiance curves that at low irradiances (below $500 \mathrm{~W} / \mathrm{m}^{2}$ ) the shading did not significantly interfere with the generated power. To avoid certain shaded cells to behave as a load, it is explicit the importance of by-pass diodes and their performance.

Keywords: Photovoltaic plant. Shading. Losses.

\section{Resumen}

Debido al avance de la implementación de plantas Fotovoltaicas (FV) ubicadas en grandes centros, son necesarios estudios para analizar los factores que afectan esta generación de energía eléctrica. En este trabajo, se hace un análisis sobre el impacto de la sombra en una planta FV ubicada en la región urbana y conectada a la red eléctrica del Laboratorio de Energías Alternativas (LEA) de la UFC, campus Pici, Fortaleza- CE. Antes de cada experimento se realizó la limpieza de los módulos FV para garantizar mayor fiabilidad al estudio. Para análisis fueron generadas diferentes referencias de sombra, estáticas y dinámicas, con la intención de simular situaciones reales de no-idealidades en la planta. La sombra estática consiste en una sombra que no varía su posición a lo largo del tiempo proyectada sobre los módulos; en la sombra dinámica, la sombra varía a lo largo del tiempo. Para comparar las variables de rendimiento de la planta FV se escogieron días con medias de irradiancia semejantes mientras duraron los experimentos. Fue calculado el Factor de Capacidad (FC) para los cuatro experimentos analizados, divididos en dos situaciones de sombra estática y dos de sombra dinámica. Como resultado se obtuvo una reducción del FC de 2,35\% e $1,17 \%$ para el primero caso y de $0,84 \%$ y $1,72 \%$ para el segundo. Las curvas de potencia e irradiancia fueron observadas; se percibió que para irradiancias bajas (inferiores a 500W/ $\mathrm{m}^{2}$ ) la sombra no interfirió de modo significativo en la potencia generada. La importancia de los diodos by-pass y su actuación en evitar determinadas células con sombra de se portaren como carga fue explicitada.

Palabras-clave: Planta fotovoltaica. Sombra. Pérdidas.

\section{Résumé}

Grâce au progrès de la mise en place des cellules photovoltaïques (PV) situées dans des grands centres, des études sont nécessaires pour analyser les facteurs qui affectent cette génération d'énergie électrique. Dans le présent article, on analyse de l'impact de l'ombrage sur une cellule photovoltaïque située dans une zone urbaine et connectée au réseau électrique du Laboratoire des énergies alternatives (LEA) de l'UFC, Campus du Pici, à Fortaleza, au état du Ceará. Avant chaque expérience, les cellules photovoltaïques ont été nettoyés afin de garantir une plus grande fiabilité de l'étude. Pour l'analyse, différents modèles d'ombrage, c'est-à-dire, statiques et dynamiques ont été générés afin de simuler des situations réelles de non-idéalités dans la cellule. L'ombrage statique consiste en une ombre (dont la position ne varie pas pendant le temps) projetée sur des cellules; l'ombrage dynamique, à son tour, l'ombre varie pendant le temps. Pour comparer les variables de performance de la cellule photovoltaïque, on a choisi des jours dont les moyennes d'irradiance on été similaires pendant la période des expériences. On a calculé le Facteur de Capacité (FC) pour les quatre expériences analysées. Ils ont été divisés en deux situations d'ombrage statique et deux d'ombrage dynamique. On a pu trouvée une réduction du $\mathrm{FC}$ de $2,35 \%$ et $1,17 \%$ pour le premier cas et de $0,84 \%$ et $1,72 \%$ pour le second. II faut noter que les courbes de puissance et d'irradiance ont été observées. II a été constaté qu'à des irradiations faibles (inférieures à $500 \mathrm{~W} / \mathrm{m}^{2}$ ), l'ombrage n'a pas interféré de manière significative avec la puissance générée. L'importance des diodes de by-pass et leur efficacité pour éviter que certaines cellules ombragées se comportent comme une charge ont été explicitées.

Mots-clés: Cellule photovoltaïque. Ombrage. Pertes. 


\section{Introdução}

As fontes renováveis ganham mais espaço na matriz energética mundial a cada dia. Em especial, a geração fotovoltaica (FV) destaca-se pelo seu notório crescimento nos últimos anos, seja em aplicações de sistemas isolados, presentes em áreas remotas, seja em sistemas diretamente conectados à rede. Países desenvolvidos, como China, Japão, Estados Unidos e Alemanha, foram líderes em capacidade instalada nos últimos anos (IEA, 2018).

No Brasil, houve um aumento de 0,1\%, a capacidade instalada FV em 2016, para 0,6\%, em 2017 (EPE, 2018). O governo brasileiro vem desenvolvendo políticas para diversificar a matriz de geração de eletricidade do país. Com relação à micro e minigeração distribuída de energia elétrica, o crescimento foi incentivado por ações regulatórias, tais como a que estabelece a possibilidade de compensação da energia elétrica excedente produzida em plantas de menor porte (net metering).

A tecnologia FV possui a capacidade de gerar eletricidade de forma silenciosa e sua instalação é feita em módulos, desde baixas potências, como no caso das microgerações, até as grandes potências, nas denominadas usinas solares. O grande diferencial da geração FV é sua integração ao ambiente, ao envelope das edificações e aos equipamentos urbanos, de forma integrativa, permitindo que determinado espaço tanto abrigue quanto produza energia elétrica, o que possibilita gerar eletricidade junto ao ponto de consumo, minimizando perdas de transmissão e distribuição inerentes à energia entregue por centrais geradoras convencionais (BORGES NETO; CARVALHO, 2012).

Diante das vantagens explicitadas no parágrafo acima, surgem desvantagens, inerentes a todos esses benefícios. O ótimo funcionamento de painéis $\mathrm{FV}$ depende do fornecimento de máxima irradiação possível ao longo de todo o período diurno. Além disso, plantas FV, principalmente aquelas instaladas em zonas urbanas, estão sujeitas a fatores de não idealidade, isto é, fatores que desviam das condições padrões de funcionamento e que afetam o desempenho da geração. Entre esses fatores podemos destacar: sombreamento, temperatura, maresia, umidade, reflexão e sujidade.

Dentre as não idealidades citadas, uma das mais frequentes é a devida ao sombreamento. Toda planta FV está sujeita a sombras projetadas por elementos em seus arredores, como árvores, prédios, postes, torres e cabos elétricos provenientes da rede de distribuição de energia elétrica. Além desses eventos, pode ocorrer sombreamento devido à sujeira, causada, principalmente, por poeira do solo ou dejetos de pássaros, além do sombreamento dinâmico das nuvens. Na Figura 1 são mostradas possibilidades reais de sombreamento em zona urbana, ocasionadas por árvores ou edificações nas vizinhanças da planta FV.

Figura 1 - Sombreamento por árvores (figura à esquerda) e por construções vizinhas (figura à direita)
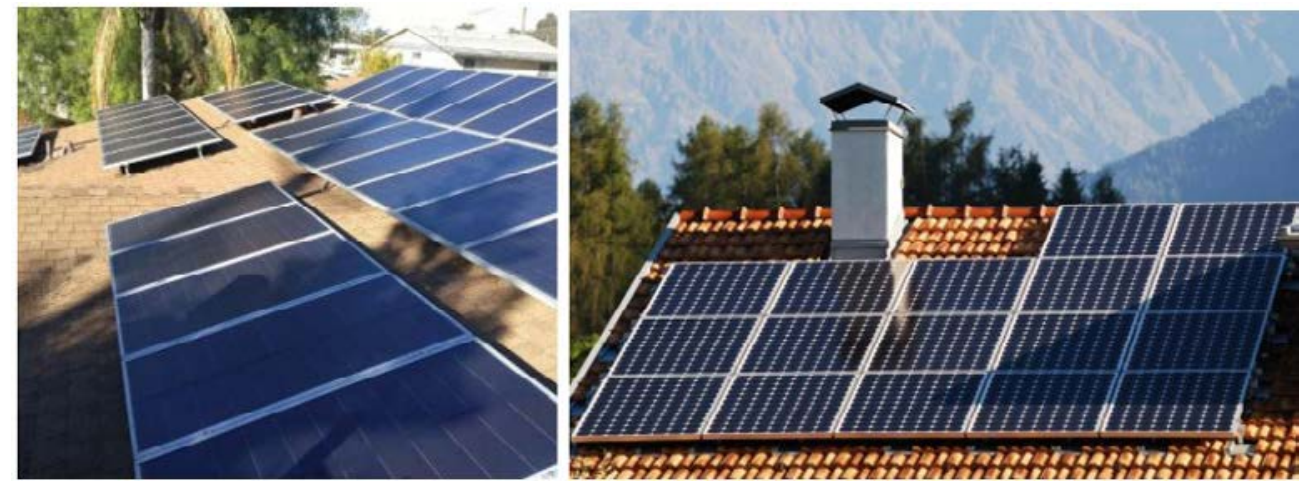

Fonte: Google Imagens, 2018.

O sombreamento pode ser total, quando algum objeto do ambiente atua como anteparo, gerando uma sombra sob a planta FV. Nesse caso, pode ocorrer a interrupção total da captação de radiação solar pelo módulo, fazendo-o deixar de produzir energia e, dependendo da topologia de ligação entre os painéis, pode 
interferir em todo o sistema de geração. Também pode ocorrer um sombreamento parcial, no qual a sombra de algumas células interfere na geração do módulo.

Os módulos de silício cristalino (c-Si) são compostos por células FV associadas em série e em paralelo. Caso uma ou mais células recebam menos irradiação solar do que outras da mesma associação, haverá uma limitação de corrente para todo o conjunto série e, consequentemente, perda de potência no gerador FV. Uma das causas para a redução da irradiação incidente é o sombreamento do módulo.

Quando um caso de sombreamento acontece, há riscos de danos no módulo parcialmente sombreado, uma vez que a potência elétrica gerada é dissipada no módulo afetado. Nesse caso pode ocorrer o fenômeno conhecido como "ponto quente", do inglês hotspot, que produz intenso calor sobre a célula afetada, com possibilidade de ruptura do vidro e fusão de polímeros e metais (PINHO; GALDINO, 2014).

Na Figura 2, é mostrada a comparação entre as curvas I-V, com e sem o efeito do sombreamento, para 4 módulos conectados em série, com e sem o uso de diodo by-pass. Para o caso com sombreamento em uma célula, como a corrente de uma diminui, consequentemente a corrente do conjunto também diminui.

Figura 2 - Curva I-V para 4 módulos com e sem sombreamento

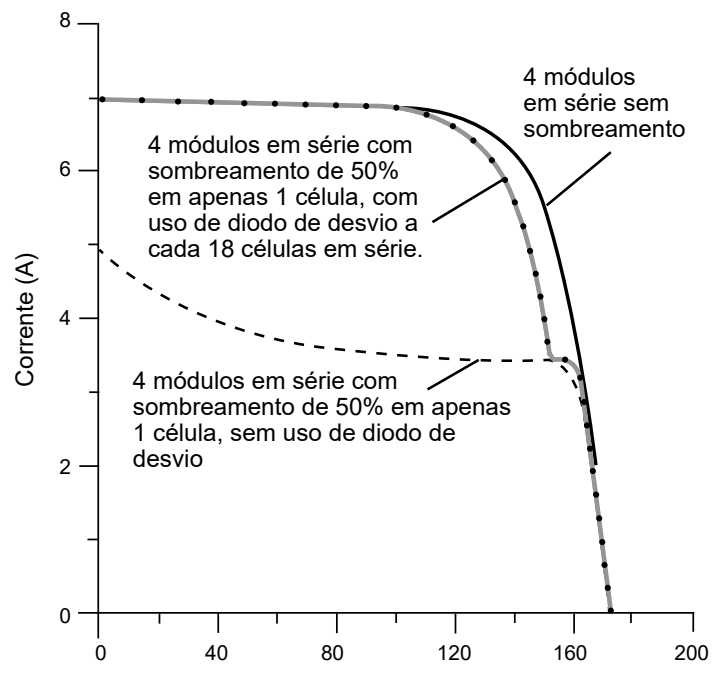

Fonte: Pinho e Galdino, 2014.

O diodo de desvio, do inglês bypass, evita a ocorrência de "pontos quentes". Por oferecer um caminho alternativo para a corrente, também limita a dissipação de potência no conjunto de células sombreadas. Desta forma, reduz tanto a perda de energia como protege o módulo do risco de danos irreversíveis. Esses diodos são ligados em cada conjunto de 15 a 30 células, e seu funcionamento é explicado na Figura 3.

Figura 3 - Operação de um diodo de desvio

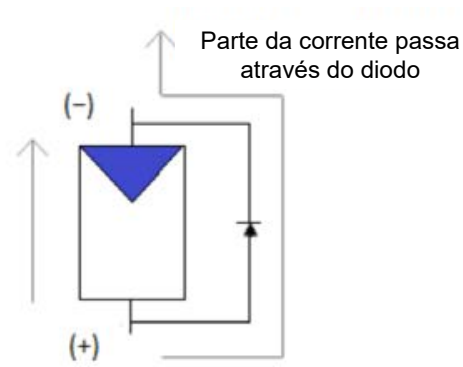

Elemento muito sombreado ou com defeito

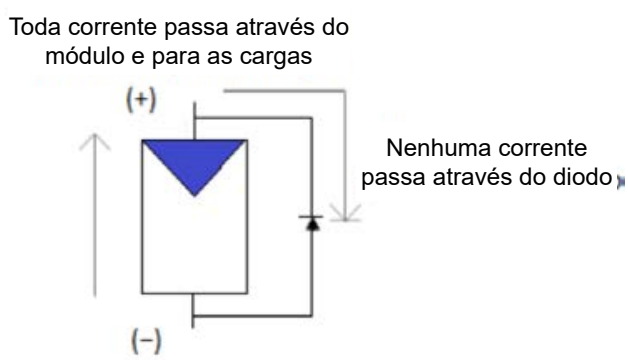

Elemento normal, pouco sombreamento ou com pouco descasamento

Fonte: Adaptado de Pinho e Galdino, 2014. 
Dada a contextualização acerca do tema tratado, como objetivo para este artigo propõe-se estudar o desempenho sob diferentes condições de sombreamento de uma planta FV conectada à rede elétrica, bem como analisar possíveis perdas devidas a esse fenômeno.

\section{Metodologia}

Com base na teoria encontrada na literatura é possível comparar o desempenho da planta FV em estudo nas diferentes condições de sombreamento propostas. Podem-se classificar os experimentos realizados como sombreamento estático e dinâmico. O primeiro refere-se a uma sombra que não varia sua posição ao longo do tempo em relação ao sol. Em contrapartida, para a segunda situação, ocorre a variação no posicionamento da sombra projetada pelo sol.

Para avaliar o efeito do sombreamento nos painéis FV, deve-se anular ou, no mínimo, diminuir ao máximo todas as variáveis adversas ao sistema, ou seja, todas as não idealidades que, além do sombreamento, também interfiram na geração FV.

Em relação à literatura revisada, é perceptível que os estudos envolvendo sombreamento são baseados em simulações computacionais em condições padrões de teste (STC - Standart Test Conditions), com traçadores de curvas PV e I-V ou com painéis/strings de referência. No último caso, bem comum, consiste em manter os dados de uma string como sendo a referência, visto que as mesmas não idealidades que ocorrem na string de teste também ocorrem naquela de referência e, portanto, não influenciam no estudo comparativo entre as curvas.

A planta FV do LEA conectada à rede da UFC, campus do Pici, é composta por apenas uma string de 6 painéis FV, modelo YL250P-29b, de $250 \mathrm{Wp}$, conectados em série, somando uma potência total de 1,5 kWp, mostrados na Figura 4. Portanto, para este estudo, não há como comparar dados do mesmo dia. A grande dificuldade, e também o diferencial deste estudo, está nessa condição necessária à sua validação: comparar dois intervalos de tempo iguais, em dias diferentes, porém com as condições externas mais próximas possíveis um do outro e com o mínimo de variabilidade entre elas. Controlar um ambiente a sol real, com variação de irradiação, temperatura, umidade, nuvens, entre outros fatores, é desafiador.

Figura 4 - Planta da microgeração FV instalada no LEA-UFC e conectada à rede do campus do Pici

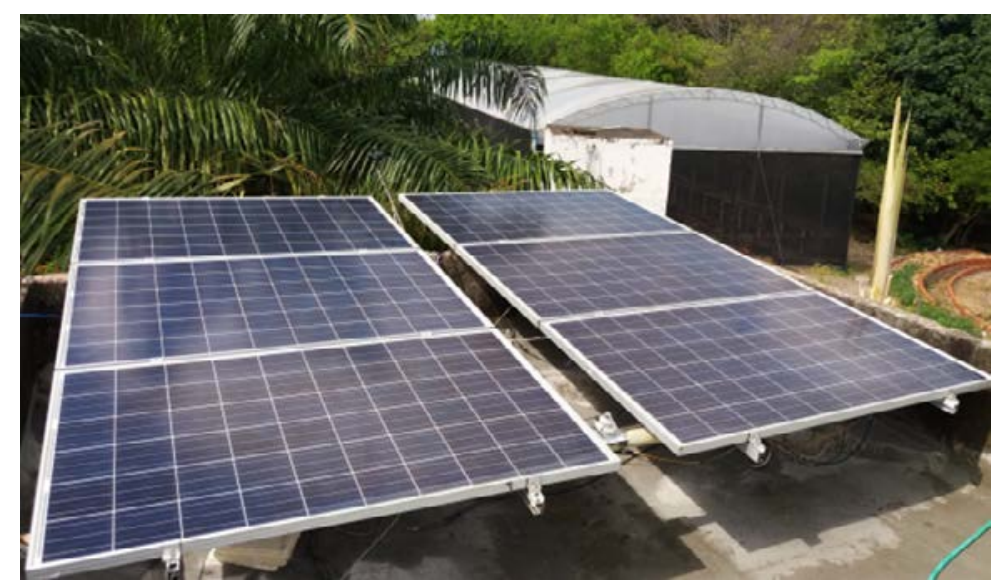

Fonte: Elaborado pelos autores, 2018.

Inicialmente, pensou-se no intervalo do dia inteiro para a realização dos experimentos, como sendo de $5 \mathrm{~h}$ às 17h. Porém, durante os experimentos, notou-se uma grande variabilidade na irradiância durante o período da manhã, mais precisamente de $5 \mathrm{~h}$ às $12 \mathrm{~h}$, o que compromete a comparação entre os dados obtidos, visto que seria muito difícil encontrar um dia de referência com comportamento semelhante. Portanto, buscou-se evitar 
realizar experimentos durante o período do início da manhã. Manteve-se um único estudo de sombreamento de dia completo, sendo o restante feito durante um intervalo de tempo pré-determinado, no período de término da manhã e no início e fim da tarde, visto ser o momento do dia em que o comportamento das variáveis externas do experimento é mais controlável e similar aos dias anteriores e posteriores.

Como embasamento teórico, para justificar a escolha e eliminar uma possível tendenciosidade ao trabalho, é mostrado que, na literatura, no comportamento climático do litoral fortalezense durante o segundo semestre, é predominante a ocorrência do fenômeno de frentes de brisa. Os ventos predominantes são os alísios, de leste. Porém, tem-se a brisa marítima durante o dia e a terrestre durante a noite. A brisa é menos intensa que os alísios. O acoplamento faz com que a direção oscile entre NE (tarde) e SE (madrugada e início da manhã). Esse acoplamento também proporciona a formação de frentes de brisa, que pode ser entendido como um encontro dessas circulações. Essas frentes formam nuvens na madrugada e início da manhã. Durante a tarde, a frente vai entrando na direção Sul, continente adentro, e aonde passa vai "limpando" as nuvens. Assim, são importantíssimas na formação de nuvens e precipitações. Por esse motivo, a chuva na cidade é mais intensa na madrugada e começo da manhã. Durante a tarde a possibilidade de chuva reduz ou, até mesmo, desaparece (PLANCHON et al., 2006; TEIXEIRA, 2008).

Além disso, por ser um estudo a sol real, durante uma determinada época temporal, isto é, o segundo semestre do ano na cidade de Fortaleza-CE, os experimentos realizados e analisados neste trabalho são feitos em irradiação média e alta. A potência máxima não apresenta redução considerável abaixo de $700 \mathrm{~W} /$ $\mathrm{m}^{2}$ de irradiância (TEO et al., 2018) e, segundo Rodrigues et al.(2018), para valores de irradiância inferiores a $580 \mathrm{~W} / \mathrm{m}^{2}$, a influência da sombra é insignificante, uma vez que a penumbra é maior que a sombra efetiva nessas ocasiões.

No início das atividades, a planta FV foi encontrada em condições de sujidade, conforme mostra a Figura 5.

Figura 5 - Sujidade encontrada nos painéis FV

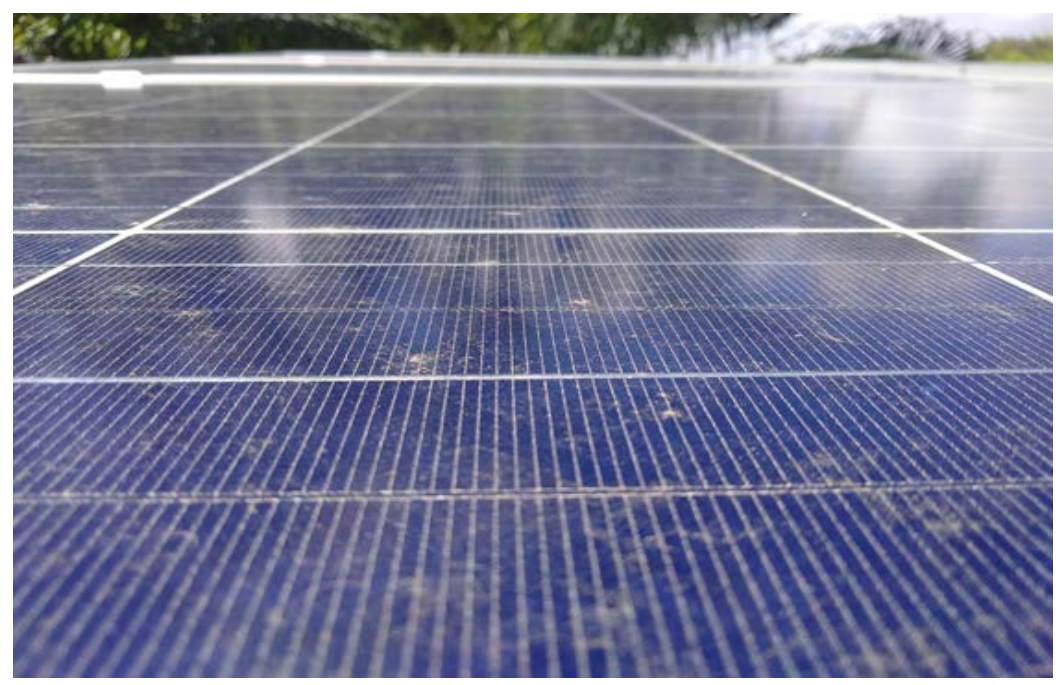

Fonte: Elaborado pelos autores, 2018.

Com relação à sujidade, estudos no Brasil e no mundo apresentaram resultados de 7 a $10 \%$ de perda máxima (RABELO, 2017). Para eliminar o efeito desse fenômeno, adotou-se um protocolo de limpeza antes da realização dos experimentos, o qual consistiu em utilizar água, sabão neutro, pano de algodão e rodo para lavagem. O procedimento foi realizado no dia 18/09/2018 e pode ser visto na Figura 6. 
Figura 6 - Limpeza dos módulos FV para evitar não-idealidades

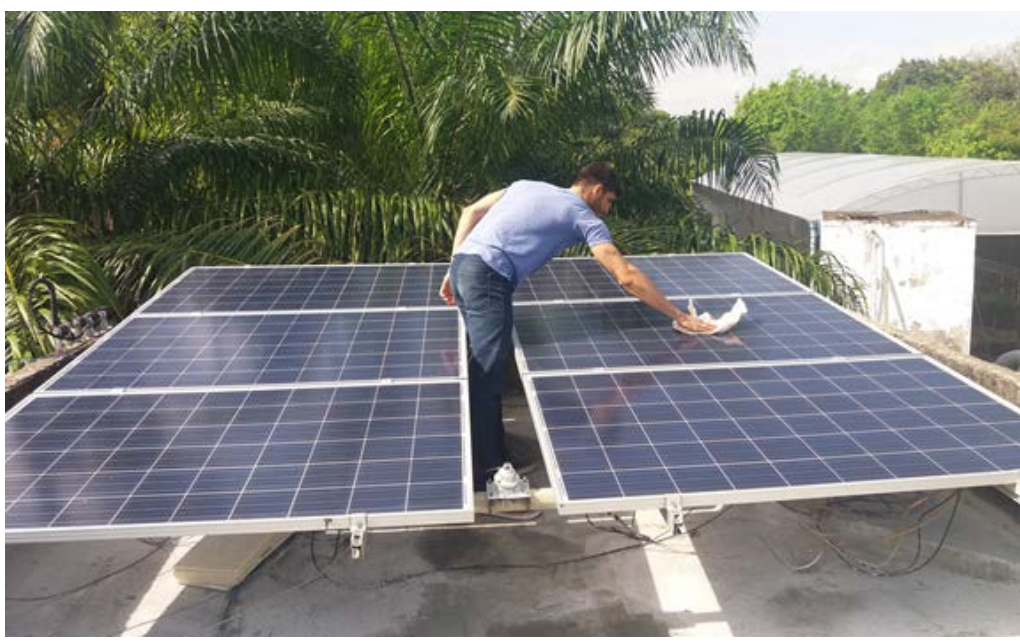

Fonte: Elaborado pelos autores, 2018.

Na planta FV estudada são utilizados dois sistemas independentes de aquisição de dados. O primeiro, mostrado na Figura 7, consiste em monitorar as variáveis elétricas da planta: tensão, corrente e potência. O segundo, explicitado na Figura 8, visa observar valores relacionados ao ambiente a que o sistema FV está submetido: dados de irradiância e temperatura ambiente.

A irradiância é salva no banco de dados do sistema de aquisição de dados ambientais a cada um minuto. Para manter o padrão dos gráficos do inversor, ajustou-se para a frequência de dez minutos por meio de métodos numéricos.

Figura 7 - Diagrama do sistema de aquisição de dados elétricos

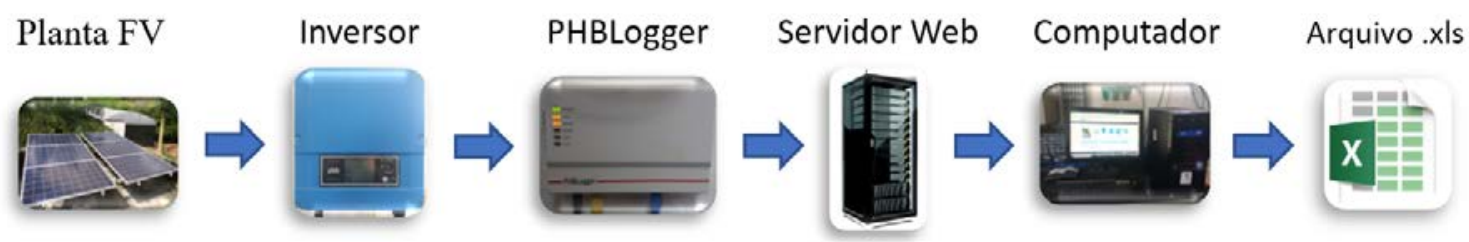

Fonte: Elaborado pelos autores, 2018.

Figura 8 - Diagrama do sistema de aquisição de dados ambientais Piranômetro

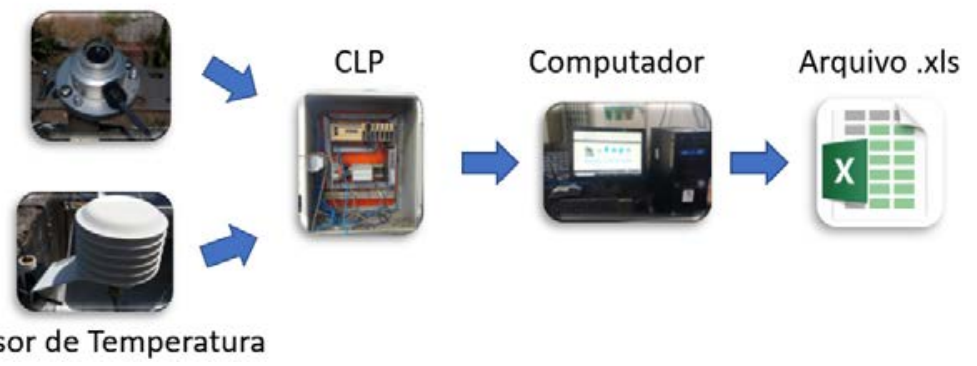

Fonte: Elaborado pelos autores, 2018. 
Um fato observável na Figura 9 é a sobreposição entre as curvas de potência e irradiância. Isto acontece porque a potência gerada depende da quantidade de irradiação incidida sobre os módulos FV. Neste gráfico, utilizou-se o dia 21/09/2018 como exemplo. No decorrer de todos os experimentos realizados, o pico de geração concentrou-se próximo às $11 \mathrm{~h}$, assim como no dia mostrado abaixo.

Figura 9 - Curvas de potência e irradiância sobrepostas para o dia 21/09/2018

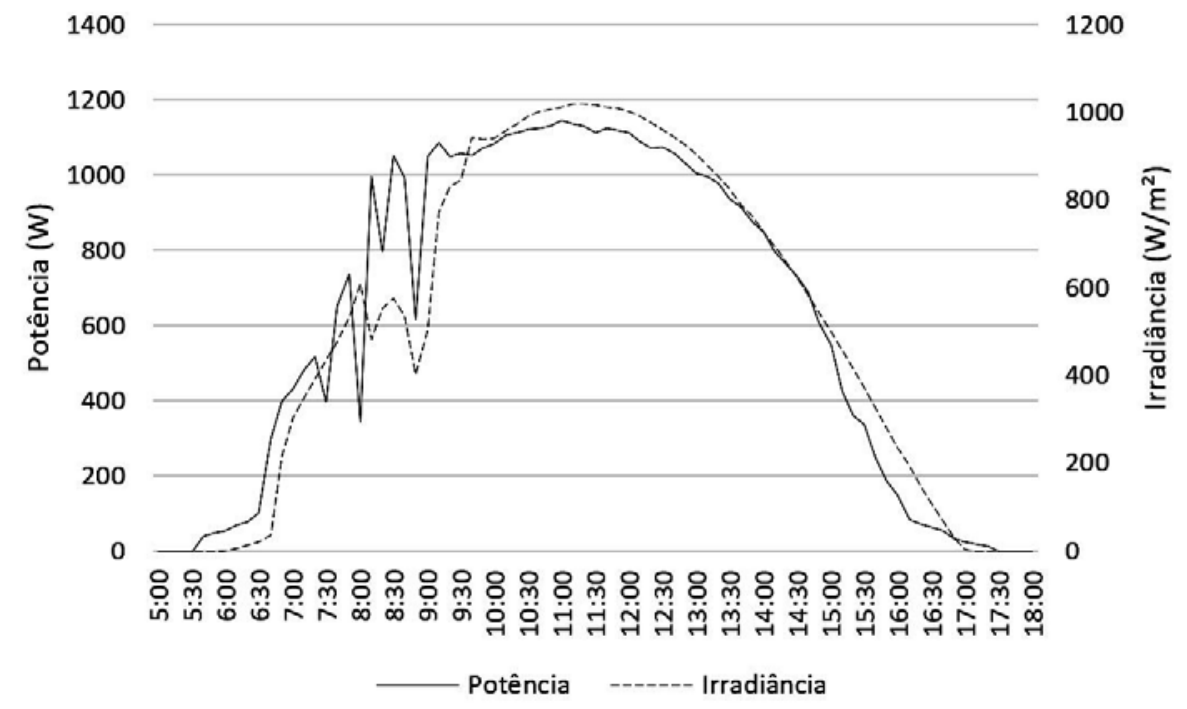

Fonte: Elaborado pelos autores, 2018.

Como critério de análise de desempenho da planta FV, calculou-se o FC para cada dia estudado. A potência nominal do sistema FV é de 1,5 kWp. O FC é a proporção entre a produção efetiva da planta em um período de tempo e a produção nominal nesse mesmo período (PICANÇO; ROLIM; PONTE, 2018).

Como base para a proporção de produção de eletricidade, medidas do FC da planta FV analisada para o período de setembro de 2016 a agosto de 2017 são mostradas na Figura 10.

Figura 10 - FC da planta FV analisada

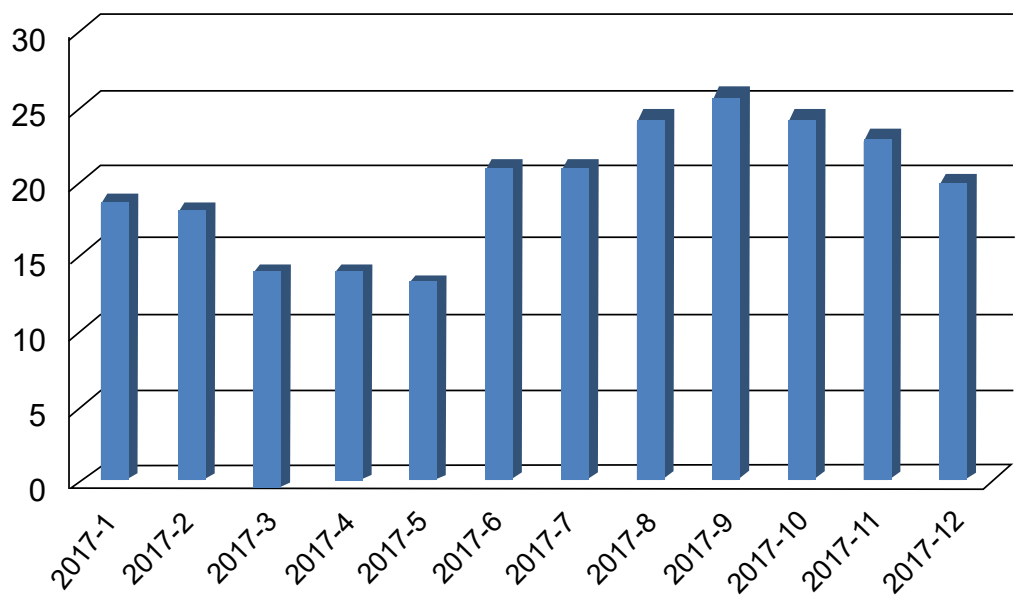

Fonte: Carvalho et al., 2018. 
O FC calculado mostra claramente a influência das condições meteorológicas do local: predominantemente chuvoso de janeiro a junho e com poucas chuvas no restante do ano. Um FC médio de $20 \%$ é calculado no período mencionado (CARVALHO et al., 2018).

\section{Experimentos e análise de dados}

\subsection{Sombreamento estático}

Para a realização do experimento de sombreamento estático, foi utilizada uma placa de madeira em formato retangular, medindo $1,20 \mathrm{~m} \times 0,75 \mathrm{~m}$, o que representa uma área coberta de $0,9 \mathrm{~m}^{2}$. Este experimento foi realizado de dois modos.

\section{- Experimento 1}

O experimento de sombreamento estático foi realizado de 9 h30 às $18 \mathrm{~h}$ do dia 18/09/2018. Utilizou-se a escada para o acesso da planta FV e fotografou-se apenas o início do teste, visto que a placa permaneceu estática durante o resto do dia, provocando a mesma sombra ao longo do tempo. O dia 21/09/2018, o qual em que não houve sombreamento, foi utilizado como referência comparativa. Na Figura 11 é possível verificar a disposição física da placa retangular na planta FV.

Figura 11 - Experimento de sombreamento estático realizado no dia 18/09/2018

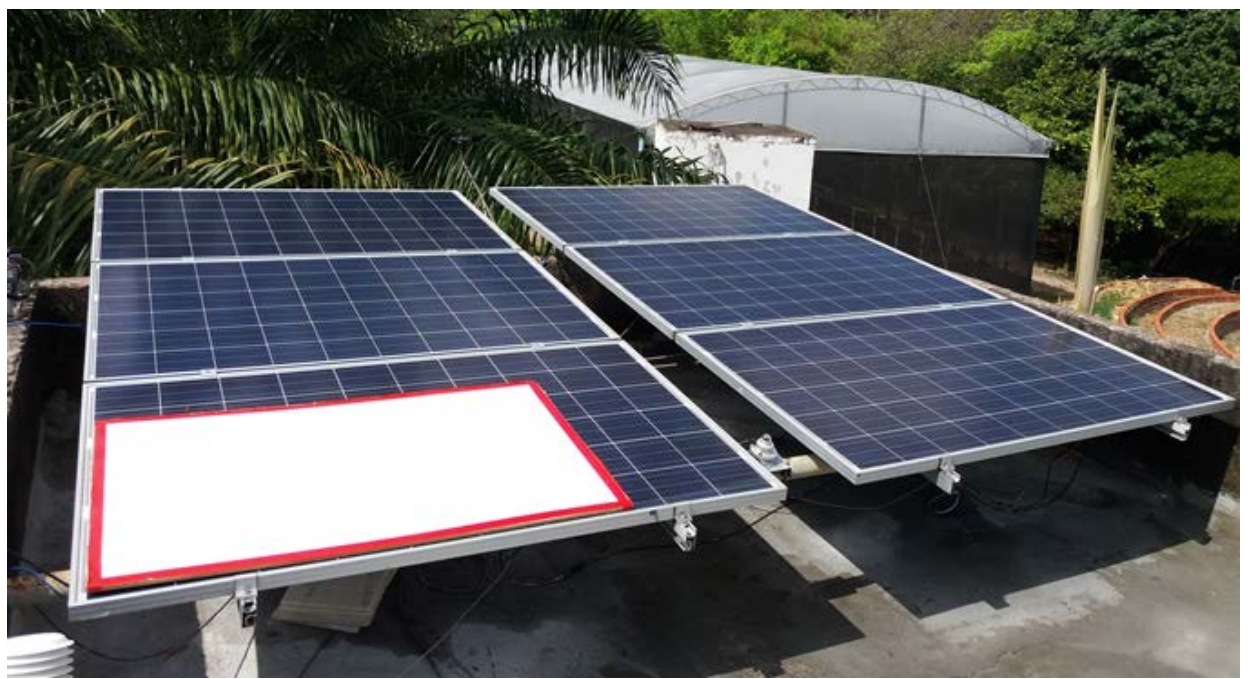

Fonte: Elaborado pelos autores, 2018

A irradiação entre os dias 18/09/2018 e 21/09/2018, durante o período de $9 \mathrm{~h} 30$ às $18 \mathrm{~h}$, foi calculada e sintetizada na Tabela 1.

Tabela 1 - Irradiações médias durante o período do experimento de sombreamento estático

\begin{tabular}{c|c|c}
\hline Período & Data & Irradiação $\left(\mathrm{kWh} / \mathrm{m}^{2}\right)$ \\
\hline \multirow{2}{*}{$9 \mathrm{~h} 30$ às 18h } & $18 / 09 / 2018$ & 5,417 \\
\cline { 2 - 3 } & $21 / 09 / 2018$ & 5,452 \\
\hline
\end{tabular}

Fonte: Elaborado pelos autores, 2018. 
Conforme mostrado na Figura 12, é perceptível a similaridade entre os dias escolhidos. Com essa proximidade garantida, é validada a comparação de potência entre os dias com a planta FV sombreada e não sombreada, mostrada na Figura 13.

Figura 12 - Irradiância comparativa entre os dias 18/09/2018 e 21/09/2018

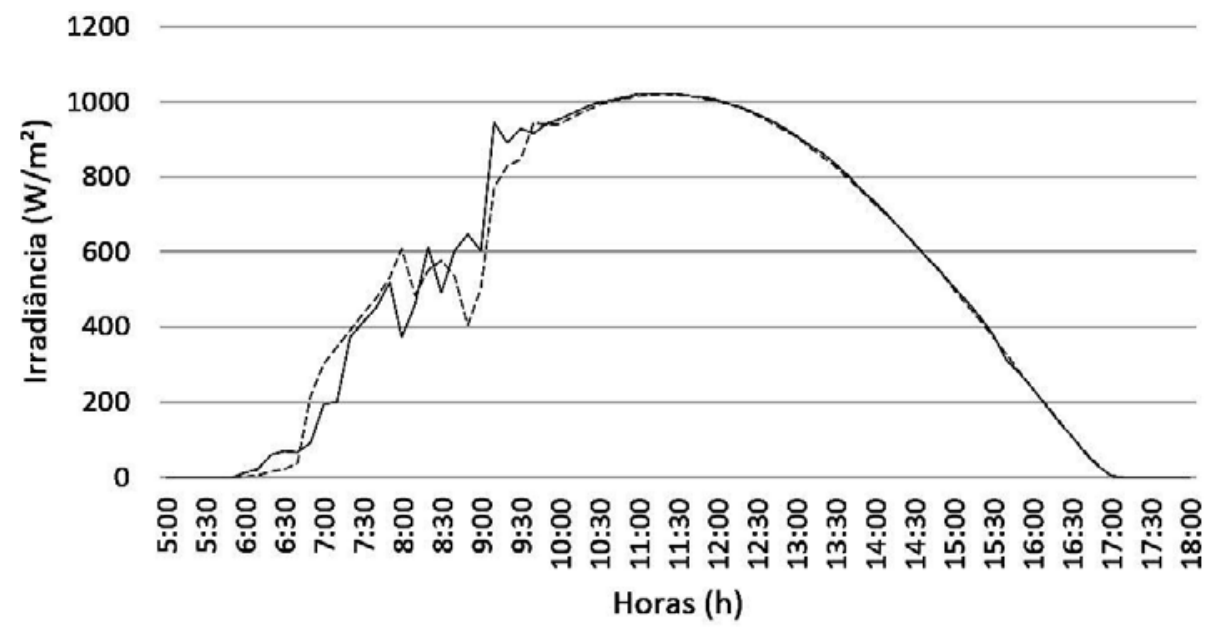

Dia 18/09/2018 ------- Dia 21/09/2018

Fonte: Elaborado pelos autores, 2018.

Figura 13 - Potência comparativa entre os dias 18/09/2018 e 21/09/2018

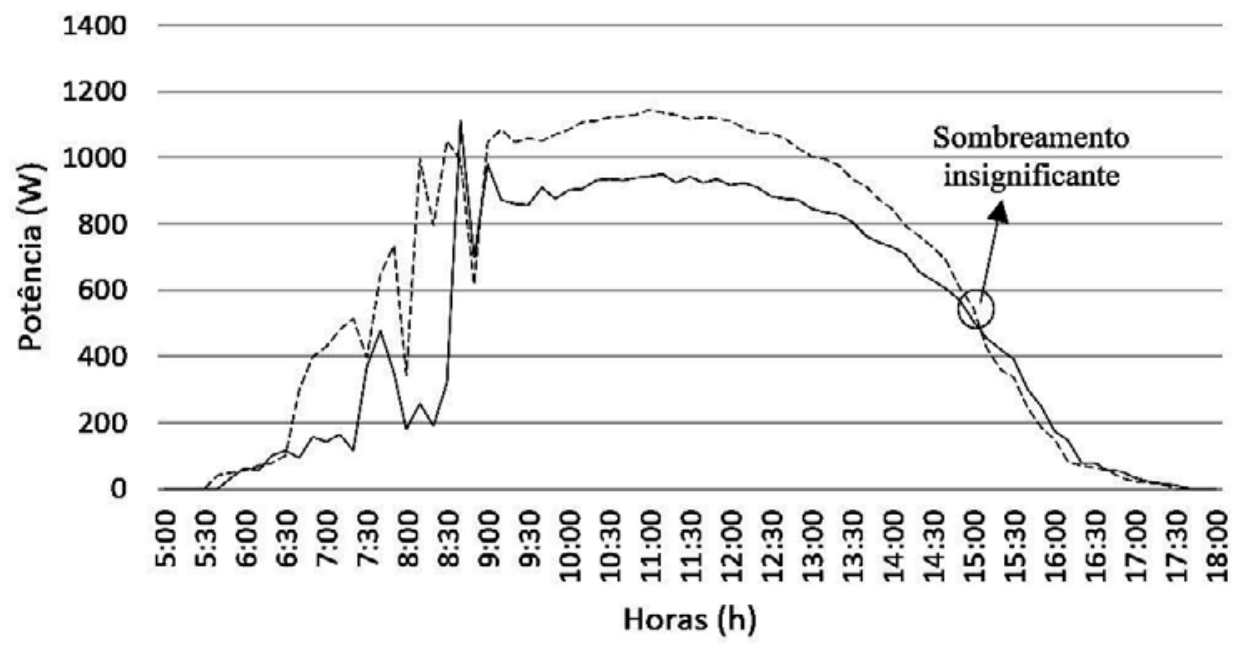

Dia $18 / 09 / 2018$

Dia $21 / 09 / 2018$

Fonte: Elaborado pelos autores, 2018.

Conforme apresentado, há uma diminuição na potência gerada em decorrência do sombreamento estático. Considerando que o sombreamento foi realizado a partir das $9 \mathrm{~h} 30$, um detalhe a ser inferido pelo comportamento das curvas é que, para baixas irradiâncias, não interfere de modo significativo na potência gerada da planta FV. O valor de irradiância para o qual o sombreamento passou a ser insignificante foi aquele relativo ao horário de $15 \mathrm{~h}$, que corresponde ao valor de $501,3 \mathrm{~W} / \mathrm{m}^{2}$. 
Para o cálculo do FC foi considerado o período de $09 \mathrm{~h} 30$ às $18 \mathrm{~h}$, intervalo de duração do experimento e períodos das irradiâncias dos dias semelhantes analisados. Assim:

$$
F C(\%)=\frac{E g(k W h)}{P_{\text {nom }} x \Delta t}
$$

Onde:

Eg - Energia elétrica gerada pela planta FV no intervalo $\Delta \mathrm{t}$, em $\mathrm{kWh}$.

$P_{\text {nom }}$ - Potência nominal FV, em kW.

$\Delta \mathrm{t}$ - Tempo analisado, em horas.

A eletricidade gerada é calculada como a integral da curva de potência $P(t)$ entre os instantes $t_{1}$ e $t_{2}$ relativos ao $\Delta \mathrm{t}$ considerado, sendo matematicamente escrita por:

$$
E g=\int_{t_{1}}^{t_{2}} P(t) d t
$$

Na Tabela 2 foi feita a síntese do cálculo do FC para o experimento 1.

Tabela 2 - Fator de capacidade referente ao experimento 1 de sombreamento estático

\begin{tabular}{c|c|c|c}
\hline Período & Data & Eg $(\mathrm{kWh})$ & $\mathrm{FC}(\%)$ \\
\hline \multirow{2}{*}{ 9h30 às 18h } & $18 / 09 / 2018$ & 5,303 & 14,73 \\
\cline { 2 - 4 } & $21 / 09 / 2018$ & 6,148 & 17,08 \\
\hline
\end{tabular}

Fonte: Elaborado pelos autores, 2018.

Portanto, houve uma redução de $2,35 \%$ no FC devido ao efeito do sombreamento estático.

- Experimento 2

No dia 08/10/2018, realizou-se o experimento de sombreamento estático de $12 \mathrm{~h} 30$ às $14 \mathrm{~h} 30$. O procedimento foi similar ao realizado no experimento 1. O dia 06/10/2018, em que não houve sombreamento, foi utilizado como comparação. A disposição física desse experimento é igual àquela mostrada na Figura 11.

A irradiação entre os dias 08/10/2018 e 06/10/2018, durante o período de $12 \mathrm{~h} 30$ às $14 \mathrm{~h} 30$, está mostrada na Tabela 3.

Tabela 3 - Irradiações médias para cada dia durante o período de experimento de sombreamento estático

\begin{tabular}{c|c|c}
\hline Período & Data & Irradiação $\left.\mathbf{( k W h} / \mathbf{m}^{\mathbf{2}}\right)$ \\
\hline \multirow{2}{*}{$12 \mathrm{~h} 30$ às $14 \mathrm{~h} 30$} & $08 / 10 / 2018$ & 1,723 \\
\cline { 2 - 3 } & $06 / 10 / 2018$ & 1,764 \\
\hline
\end{tabular}

Fonte: Elaborado pelos autores, 2018.

Conforme apresentado na Figura 14, a irradiância dos dias analisados é similar a partir das 12h30, horário de início do experimento. 
Fi gura 14 - Irradiância comparativa entre os dias 08/10/2018 e 06/10/2018

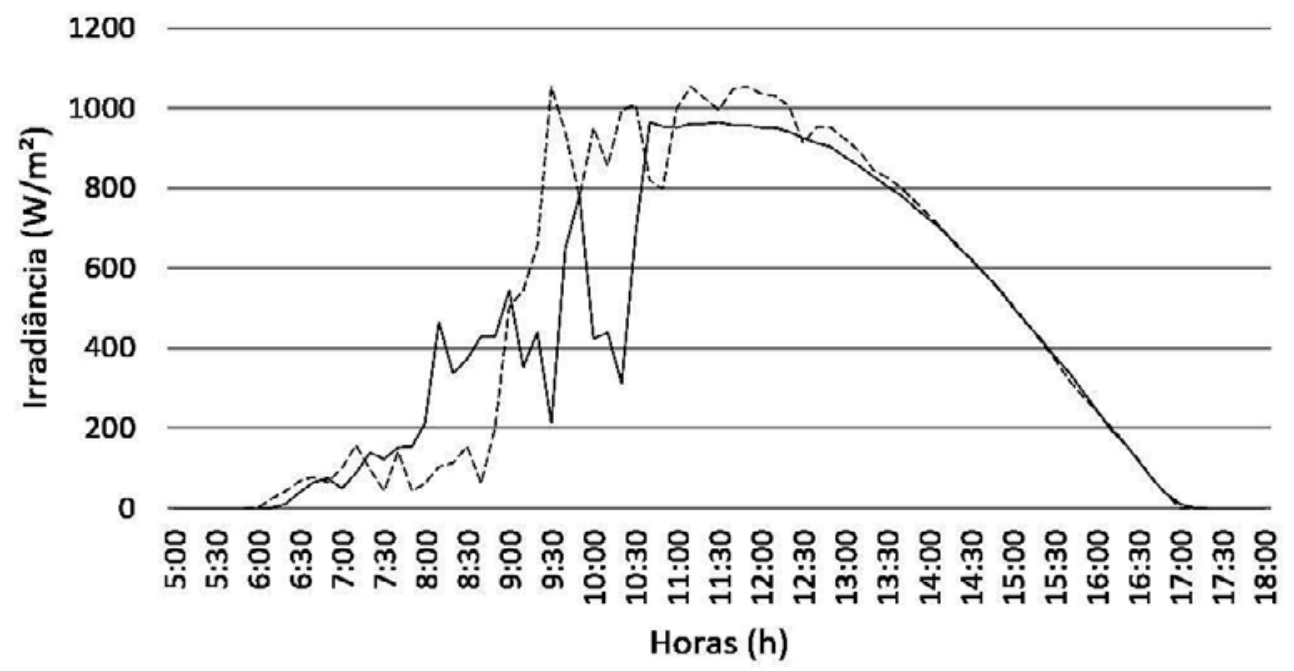

Dia $08 / 10 / 2018$

Dia 06/10/2018

Fonte: Elaborado pelos autores, 2018.

A Figura 15 mostra que as curvas de irradiância são ampliadas para o período da tarde, reiterando-se a proximidade das curvas dos dias selecionados para este caso.

Figura 15 - Irradiância comparativa ampliada para o período da tarde entre os dias 08/10/2018 e 06/10/2018

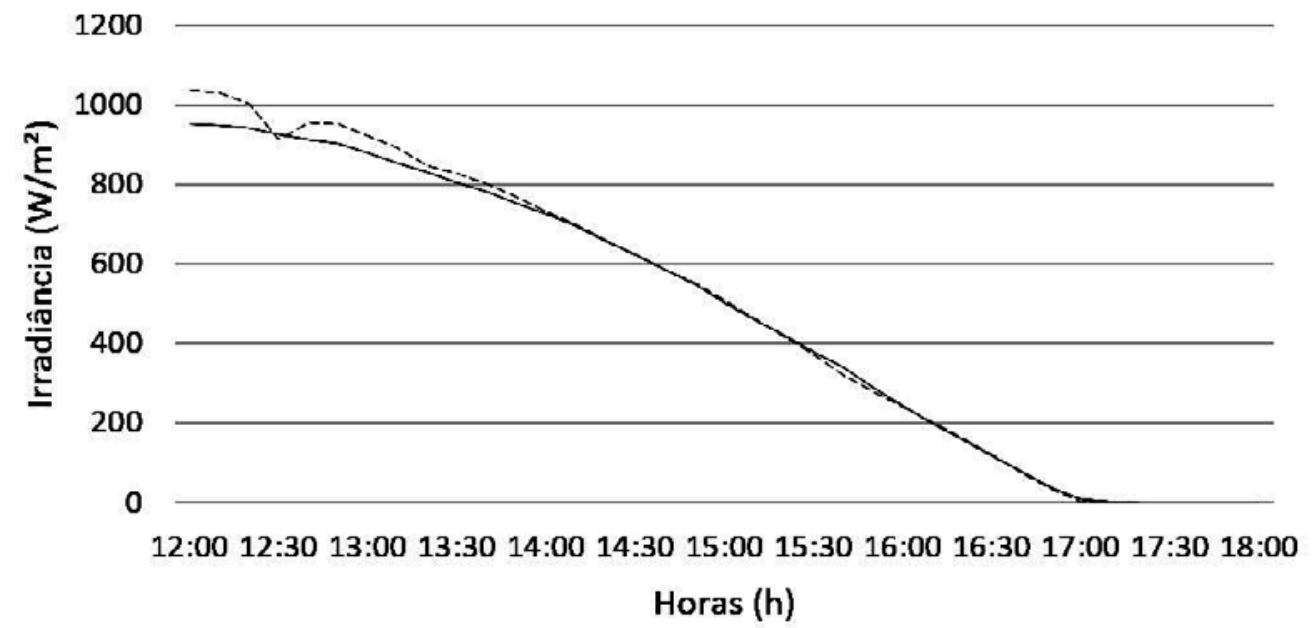

Dia 08/10/2018

Dia 06/10/2018

Fonte: Elaborado pelos autores, 2018.

Como justificado anteriormente, a variabilidade de irradiância ocorre durante o período da manhã, por esse motivo é utilizado o intervalo do término da manhã e início da tarde para o experimento. A Figura 16 apresenta as curvas de potência FV dos dias em análise. Nota-se que houve uma queda instantânea na potência entregue à rede quando um dos painéis $\mathrm{FV}$ foi sombreado com a placa retangular. 
Figura 16 - Potência FV para os dias 08/10/2018 e 06/10/2018

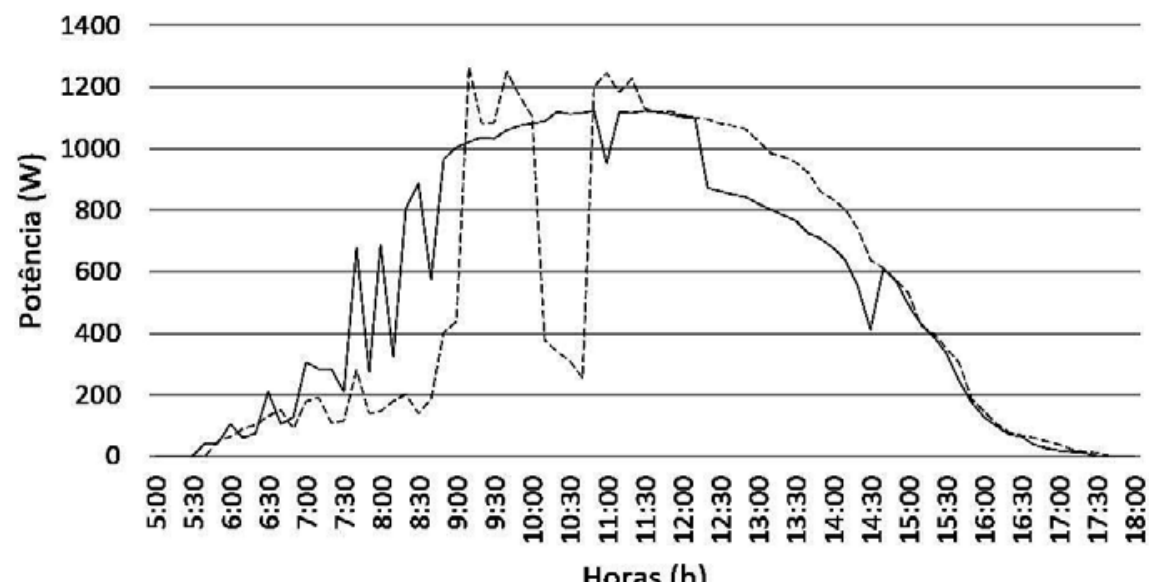

Dia $08 / 10 / 2018$

Dia 06/10/2018

Fonte: Elaborado pelos autores, 2018.

A queda de potência apresentada pode ser justificada pelo funcionamento da proteção feita pelos diodos de by-pass, que atuaram e removeram o módulo inteiro, visto que a placa sombreava os 3 conjuntos de 20 células. Portanto, a tensão da string diminuiu em 1/6, diminuindo a potência instantânea em 1/6 também. $\mathrm{Na}$ Figura 17, adaptada do datasheet do painel FV Yingli YL250P-29b da Yingli Solar, é possível verificar o comportamento explicado anteriormente, quando a placa retangular foi posicionada.

Figura 17 - Diodos de by-pass em atuação para proteger as células FV

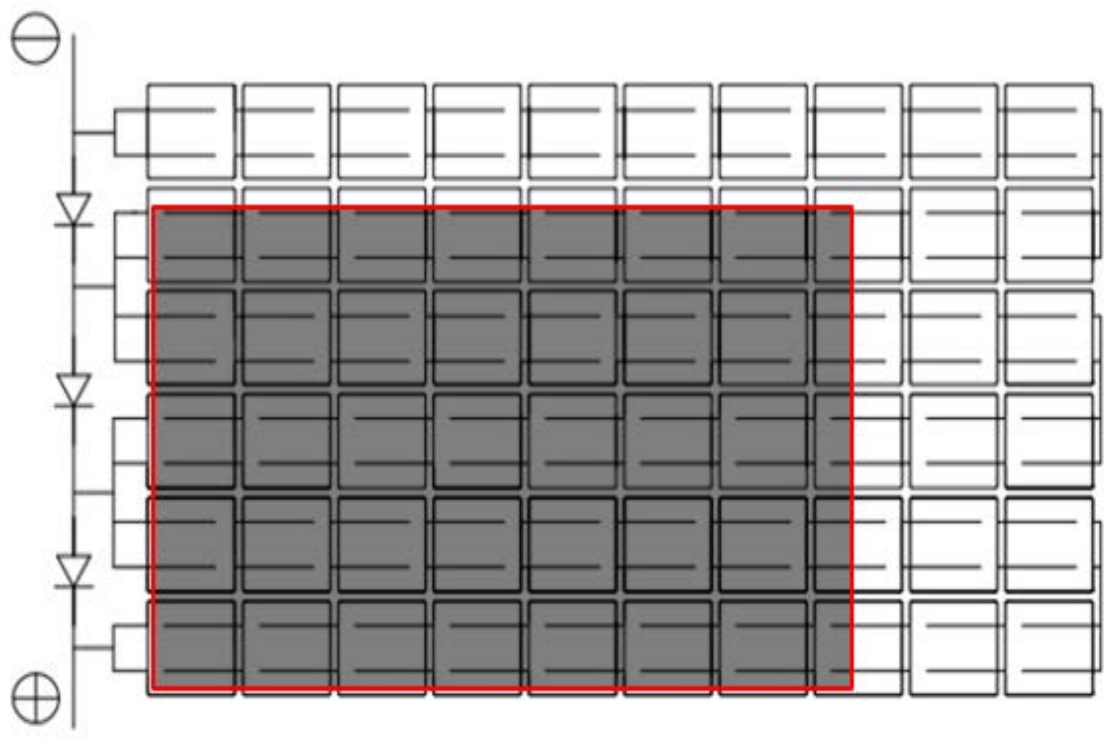

Fonte: Adaptado de Yingli Solar, 2017.

Pode-se notar que as curvas de potência seguem juntas após ser removida a sombra, confirmando que, para a mesma condição de irradiação, é gerada a mesma a potência, e que se está analisando somente o efeito do sombreamento na planta FV. 
Para o cálculo do FC, mostrado na Tabela 4, foi considerado o período de $12 \mathrm{~h} 30$ às $14 \mathrm{~h} 30$, intervalo de duração do experimento e com irradiâncias semelhantes dos aos dias analisados.

Tabela 4 - Fator de capacidade referente ao experimento 2 de sombreamento estático

\begin{tabular}{c|c|c|c}
\hline Período & Data & Eg $(\mathrm{kWh})$ & FC $(\%)$ \\
\hline \multirow{2}{*}{ 12h30 às 14h30 } & $08 / 10 / 2018$ & 1,574 & 4,37 \\
\cline { 2 - 4 } & $06 / 10 / 2018$ & 1,994 & 5,54 \\
\hline
\end{tabular}

Fonte: Elaborado pelos autores, 2018.

A redução relativa entre os $\mathrm{FC}$ é de $1,17 \%$, devido ao efeito do sombreamento estático realizado de $12 \mathrm{~h} 30$ às $14 \mathrm{~h} 30$.

\subsection{Sombreamento dinâmico}

Para a realização do experimento de sombreamento dinâmico, aquele em que a posição da sombra varia em relação à posição do sol ao longo do tempo, foi utilizada uma placa de madeira em formato retangular como anteparo, posicionada em um suporte de aço. A sombra efetiva, ao término do experimento, foi de 1,32 $\mathrm{m} \times 0,33 \mathrm{~m}$, o que representa uma área coberta de $0,44 \mathrm{~m}^{2}$. Esse experimento foi realizado de dois modos.

\section{- Experimento 1}

O experimento de sombreamento dinâmico foi realizado no dia 26/09/2018 de $13 \mathrm{~h}$ às $15 \mathrm{~h}$. Como dia de referência, foi utilizado o dia 21/09/2018. A cada hora de experimento, subiu-se na escada de acesso à laje do LEA para a captura de fotos do posicionamento da sombra ao longo do tempo, que pode ser vista na Figura 18.

Figura 18 - Experimento de sombreamento dinâmico realizado no dia 26/09/2018

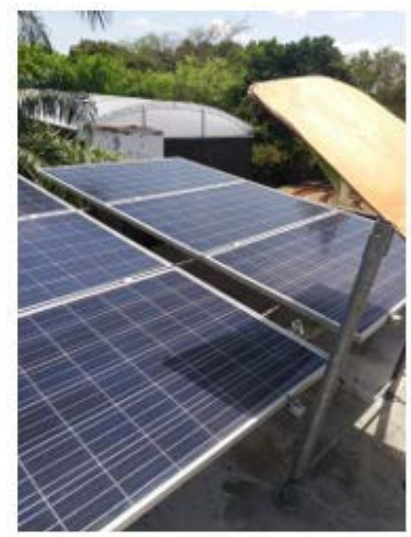

$13: 00 \mathrm{~h}$

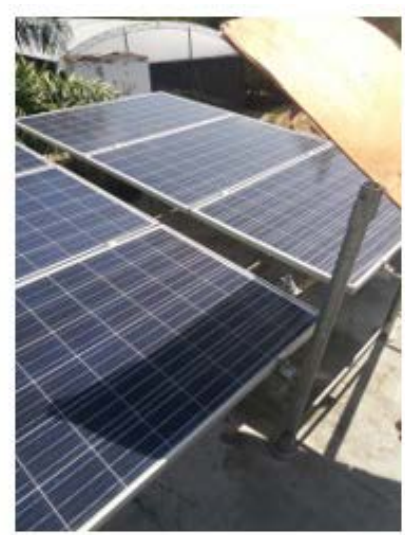

$14: 00 \mathrm{~h}$

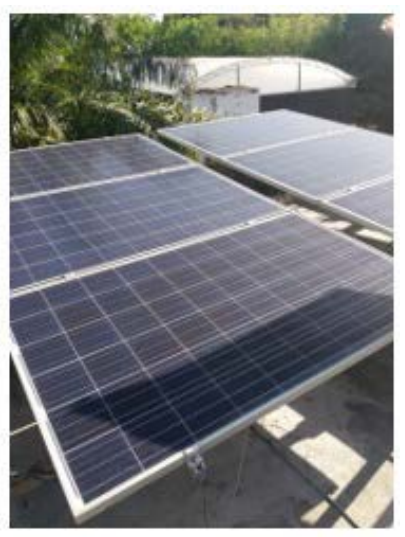

$15: 00 \mathrm{~h}$

Fonte: Elaborado pelos autores, 2018.

A irradiação entre os dias 26/09/2018 e 21/09/2018, durante o período de $13 \mathrm{~h}$ às $15 \mathrm{~h}$, foi calculada e sintetizada na Tabela 5.

Tabela 5 - Irradiações médias para cada dia durante o período de experimento de sombreamento dinâmico

\begin{tabular}{c|c|c}
\hline Período & Data & Irradiação $\left(\mathrm{kWh} / \mathrm{m}^{2}\right)$ \\
\hline \multirow{2}{*}{$13 \mathrm{~h} 00$ às 15h } & $26 / 09 / 2018$ & 1,522 \\
\cline { 2 - 3 } & $21 / 09 / 2018$ & 1,559 \\
\hline
\end{tabular}

Fonte: Elaborado pelos autores, 2018. 
Na Figura 19 são apresentadas as curvas de irradiância dos dias comparados. O dia 21/09/2018 apresentou um comportamento mais suave em relação ao dia 26/09/2018, que mostrou variações bruscas em sua curva, sendo a curva de referência concorrente com a curva para o dia com sombreamento.

Figura 19 - Irradiância comparativa entre os dias 26/09/2018 e 21/09/2018

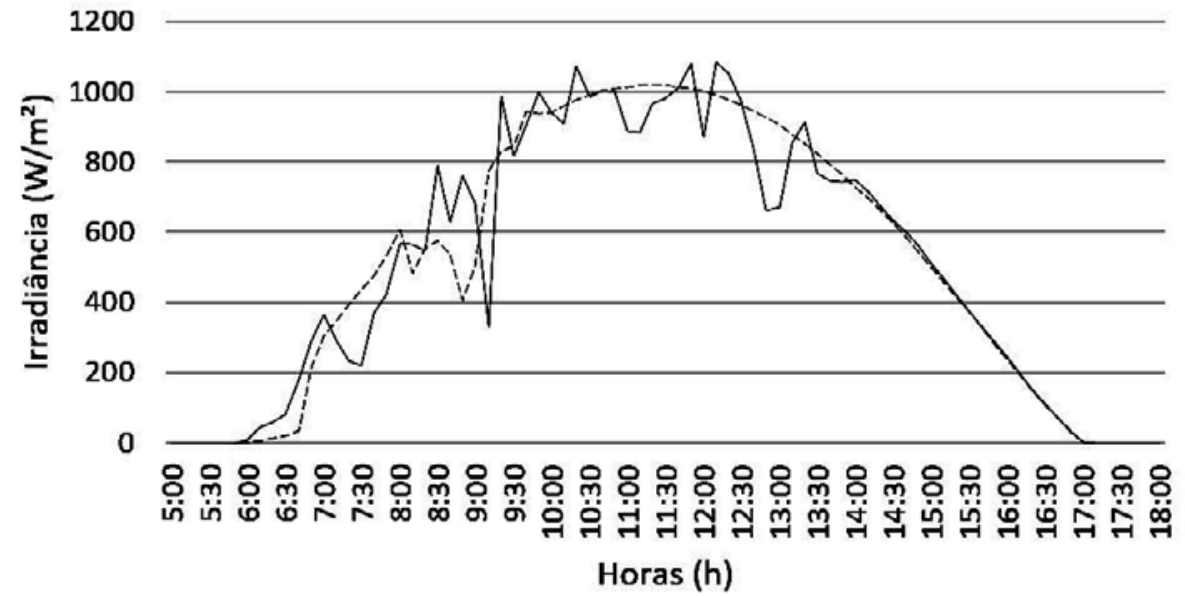

Dia 26/09/2018

Dia 21/09/2018

Fonte: Elaborado pelos autores, 2018.

Conforme a Figura 20, as irradiâncias médias dos dias no período de realização do experimento são relativamente próximas, apesar de possuírem certa variabilidade das $13 \mathrm{~h}$ às $14 \mathrm{~h}$, fato que conferiu uma dificuldade a mais para a análise deste caso.

Figura 20 - Irradiância comparativa ampliada entre os dias 26/09/2018 e 21/09/2018

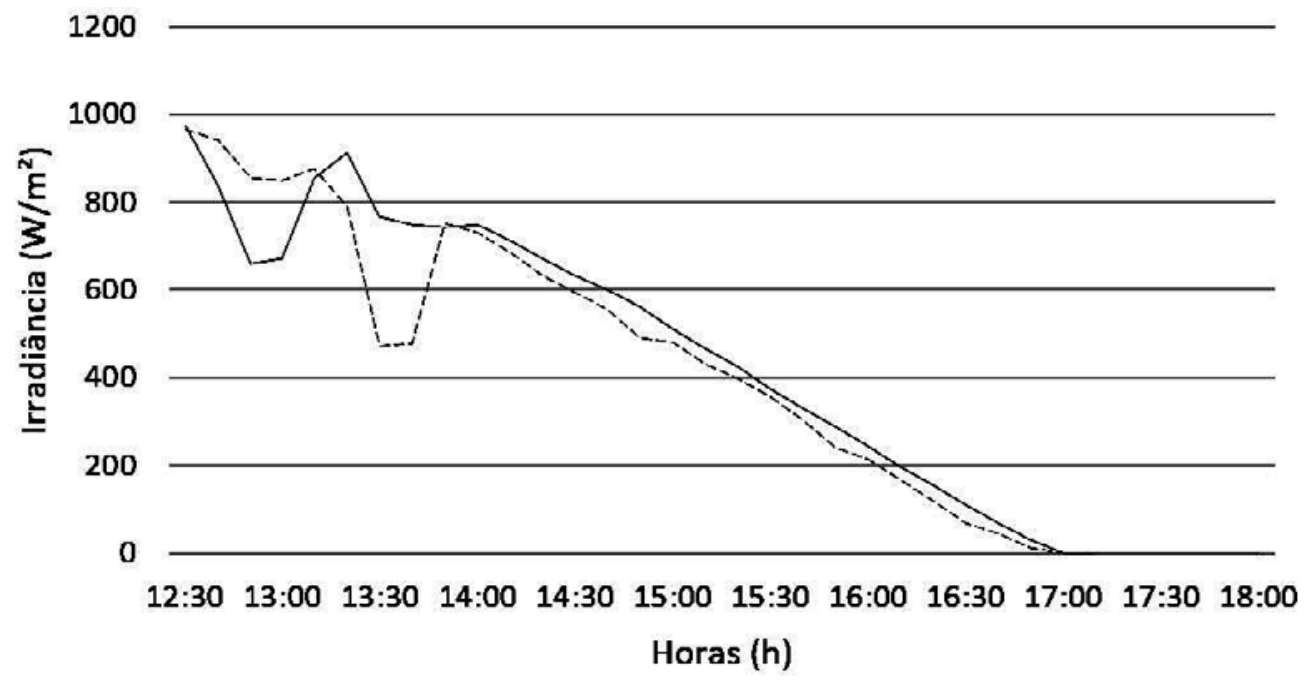

Dia 26/09/2018

Dia $21 / 09 / 2018$

Fonte: Elaborado pelos autores, 2018.

As duas curvas de potência diárias, referentes a cada respectivo dia, foram traçadas e estão mostradas na Figura 21. 
Figura 21 - Potência FV para os dias 26/09/2018 e 21/09/2018

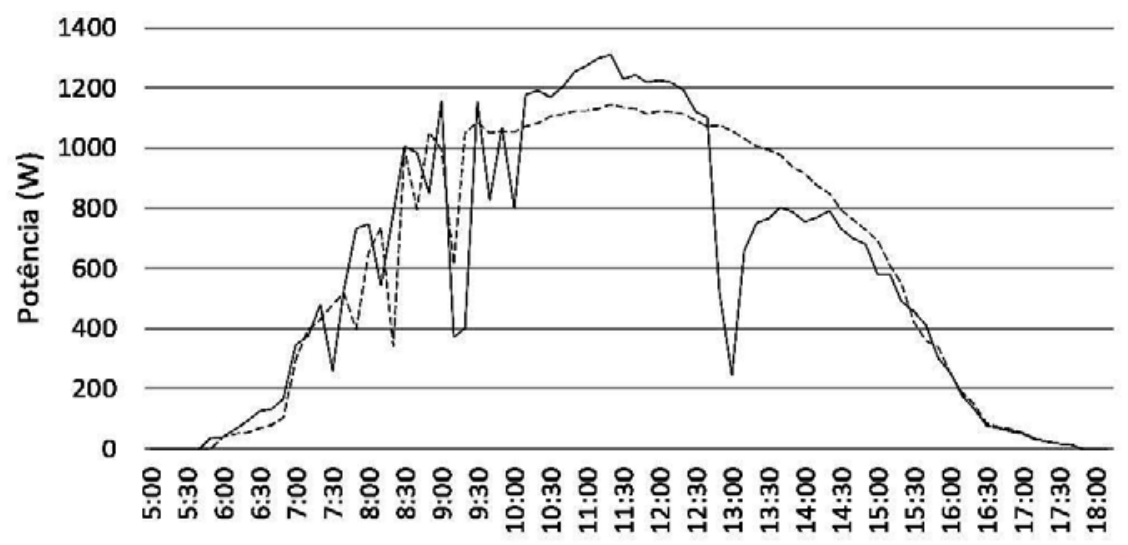

Horas (h)

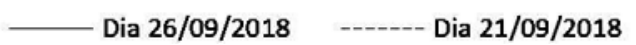

Fonte: Elaborado pelos autores, 2018.

Para esse experimento, a presente análise irá considerar o intervalo a partir das $13 \mathrm{~h}$, momento em que as irradiações dos dias são próximas. Dessa forma, o pico apresentado na geração não influenciará de forma assídua neste estudo de sombreamento.

Como pode ser visto na curva de potência, a queda ocasionada pelo sombreamento dinâmico apresenta um comportamento diferente daquele visto nos casos estáticos, em que há um deslocamento para baixo, porém mantendo o contorno da curva. Para este caso, a curva reduz para um teto de potência, que foi de 800 W. Após removida a sombra, as curvas seguem iguais, como esperado. Também é importante notar que a sombra iniciou cobrindo dois painéis $\mathrm{FV}$ e, ao final, estava presente em apenas um único painel.

Para o cálculo do FC, foi considerado o período de $13 \mathrm{~h}$ às $15 \mathrm{~h}$, intervalo de duração do experimento e com irradiações semelhantes aos dias analisados. O resultado é mostrado na Tabela 6.

Tabela 6 - Fator de capacidade referente ao experimento 1 de sombreamento dinâmico

\begin{tabular}{c|c|c|c}
\hline Período & Data & Eg $(\mathrm{kWh})$ & FC $(\%)$ \\
\hline \multirow{2}{*}{ 13h às 15h } & $26 / 09 / 2018$ & 1,560 & 4,33 \\
\cline { 2 - 4 } & $21 / 09 / 2018$ & 1,862 & 5,17 \\
\hline
\end{tabular}

Fonte: Elaborado pelos autores, 2018.

A partir da Tabela 6, é calculada uma redução de 0,84\% no FC como efeito do sombreamento dinâmico, realizado de $13 \mathrm{~h}$ às $15 \mathrm{~h}$.

- Experimento 2

No segundo experimento foi utilizado o intervalo de tempo de $10 \mathrm{~h} 30$ às $12 \mathrm{~h} 30$ do dia 27/09/2018. O protocolo de captura de fotos foi o mesmo do experimento anterior, com subida na laje do LEA a cada hora. O posicionamento da sombra ao longo do tempo está mostrado na Figura 22. Utilizou-se o dia 02/10/2018 como referência comparativa para o dia sem sombreamento. 
Figura 22 - Experimento de sombreamento dinâmico realizado no dia 27/09/2018

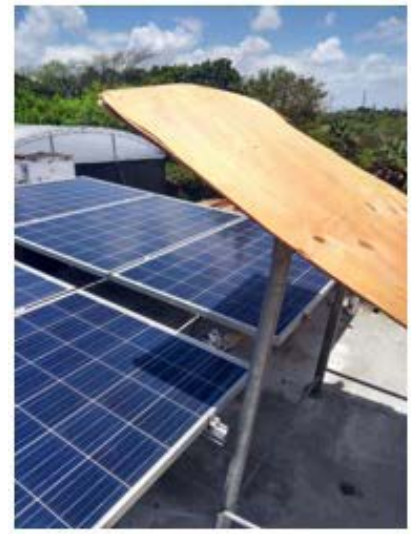

$10: 30 \mathrm{~h}$

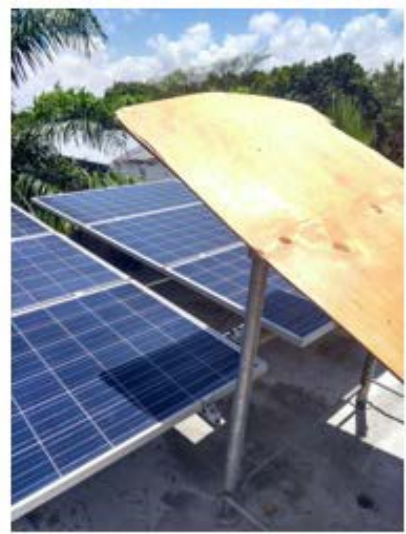

$11: 30 \mathrm{~h}$

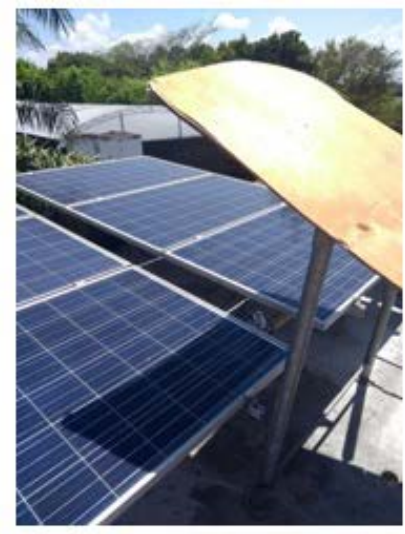

$12: 30 \mathrm{~h}$

Fonte: Elaborado pelos autores, 2018.

A irradiação entre os dias 27/09/2018 e 02/10/2018, durante o período de 10 h30 às $12 \mathrm{~h} 30$, foi calculada e sintetizada na Tabela 7.

Tabela 7 - Irradiações médias para cada dia durante o período de experimento de sombreamento dinâmico

\begin{tabular}{c|c|c}
\hline Período & Data & Irradiação $\left(\mathrm{kWh} / \mathrm{m}^{2}\right)$ \\
\hline \multirow{2}{*}{$10 \mathrm{~h} 30$ às $12 \mathrm{~h} 30$} & $27 / 09 / 2018$ & 2,091 \\
\cline { 2 - 3 } & $02 / 10 / 2018$ & 2,178 \\
\hline
\end{tabular}

Fonte: Elaborado pelos autores, 2018.

Como pode ser visto na Tabela 7, esse caso de sombreamento é feito no pico de irradiância do dia, que consiste no horário de $10 \mathrm{~h} 30$ às $12 \mathrm{~h} 30$, portanto, apresenta uma variação instantânea. A diferença média é de, aproximadamente, $0,087 \mathrm{kWh} / \mathrm{m}^{2}$, que ainda é considerado um valor próximo, tendo em vista o alto nível de irradiância desse experimento. A Figura 23 mostra que, para o período analisado, as curvas seguem uma trajetória semelhante.

Figura 23 - Irradiância comparativa entre os dias 27/09/2018 e 02/10/2018

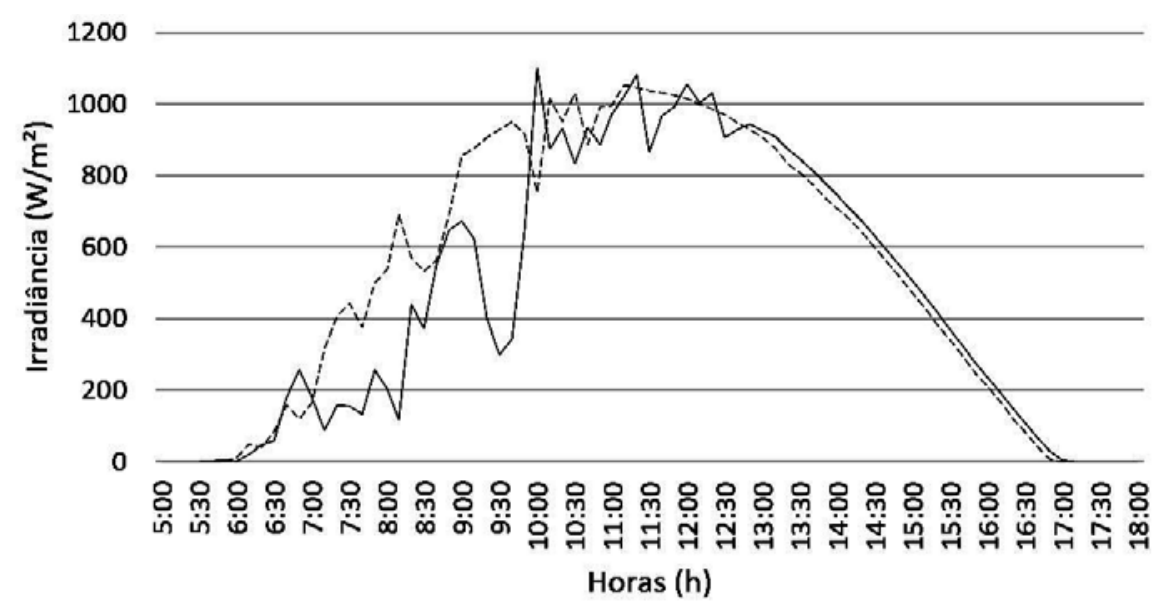

Fonte: Elaborado pelos autores, 2018. 
Ao se ampliar as curvas, é perceptível que ambas seguem juntas e, no período do experimento, a curva do dia 02/10/2018 está, na maior parte do tempo, ao lado da curva do dia 27/09/2018. Como visto, com a diferença de $0,087 \mathrm{kWh} / \mathrm{m}^{2}$ e, por se tratar de um nível de irradiância no patamar dos $1000 \mathrm{~W} / \mathrm{m}^{2}$, confere-se validade a comparação. As curvas ampliadas, referentes ao comportamento descrito, estão mostradas na Figura 24.

Figura 24 - Irradiância comparativa ampliada entre os dias 27/09/2018 e 02/10/2018
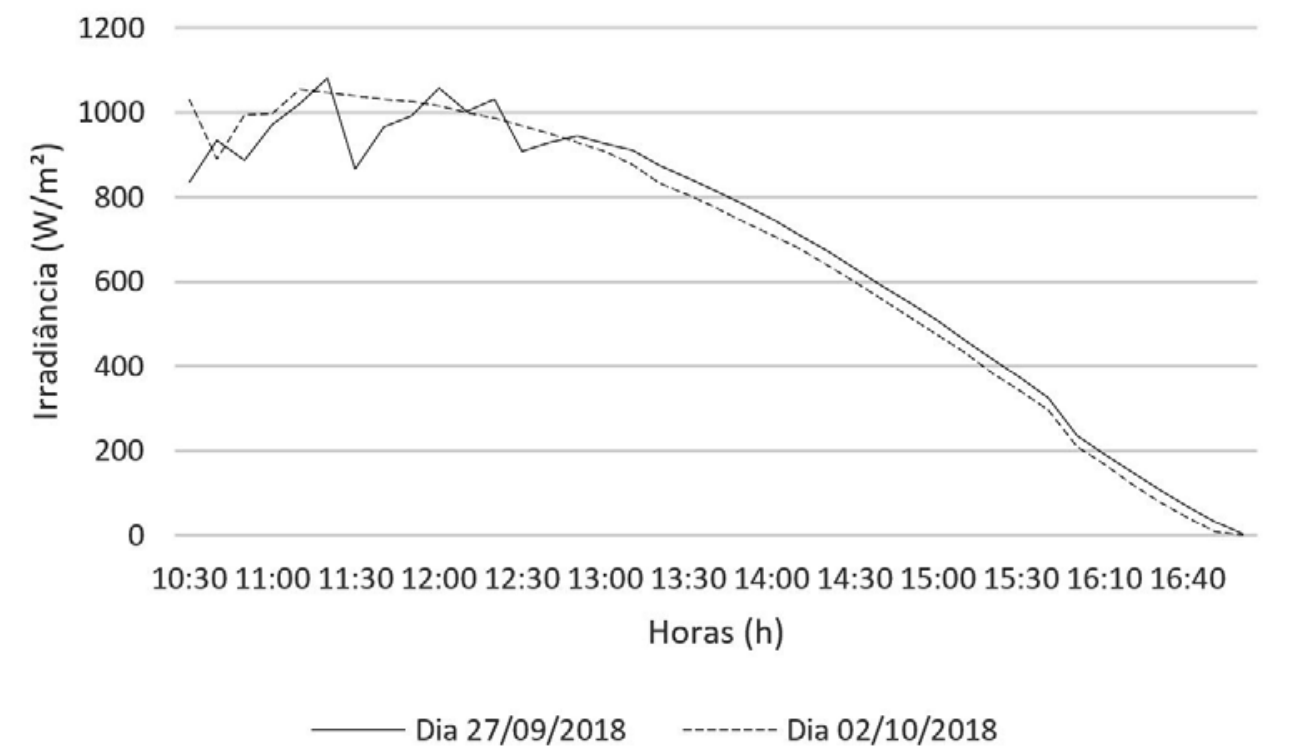

Fonte: Elaborado pelos autores, 2018.

Uma vez garantida a condição necessária para a análise de dados, as curvas de potência dos dias em estudo são traçadas e mostradas na Figura 25.

Figura 25 - Potência comparativa entre os dias 27/09/2018 e 02/10/2018

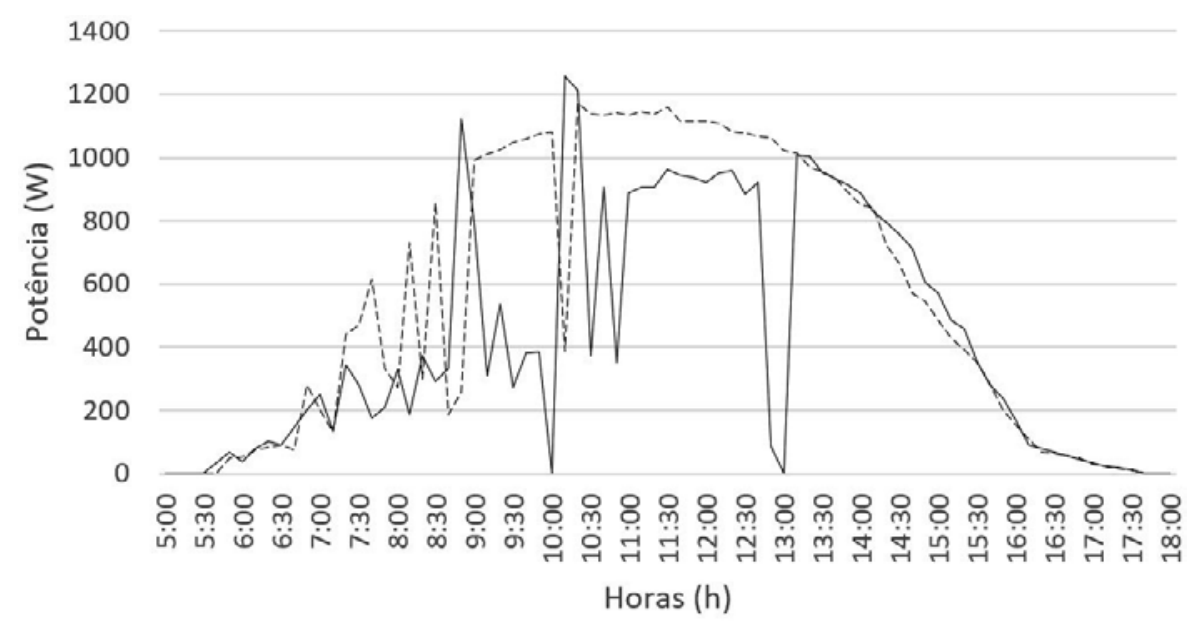

Dia 27/09/2018

Dia 02/10/2018

Fonte: Elaborado pelos autores, 2018. 
No segundo experimento de sombreamento dinâmico, realizado sob irradiância alta, a redução da curva de potência seguiu o padrão do primeiro experimento, mantendo um teto de $1000 \mathrm{~W}$. Depois de removidas as sombras, as curvas seguem próximas, conforme discutido anteriormente. Além disso, é importante notar uma diferença para o anterior: neste, a sombra iniciou cobrindo dois painéis $\mathrm{FV} \mathrm{e}$, ao final, estava presente tanto no primeiro quanto no segundo, afetando mais a geração que no anterior.

Para o cálculo do FC, mostrado na Tabela 8 , foi considerado o período de $10 \mathrm{~h} 30$ às $12 \mathrm{~h} 30$, intervalo de duração do experimento e com irradiações semelhantes ao período experimental dos dias analisados.

Tabela 8 - Fator de capacidade referente ao experimento 2 de sombreamento dinâmico

\begin{tabular}{c|c|c|c}
\hline Período & Data & Eg $(\mathrm{kWh})$ & $\mathrm{FC}(\%)$ \\
\hline \multirow{2}{*}{ 10h30 às 12h30 } & $27 / 09 / 2018$ & 1,815 & 5,04 \\
\cline { 2 - 4 } & $02 / 10 / 2018$ & 2,435 & 6,76 \\
\hline
\end{tabular}

Fonte: Elaborado pelos autores, 2018.

Pela Tabela 8 é calculado uma redução $1,72 \%$ no FC devido ao efeito do sombreamento dinâmico realizado de $10 \mathrm{~h} 30$ às $12 \mathrm{~h} 30$.

$\mathrm{Na}$ Tabela 9 são sintetizados os experimentos analisados, enfatizando o período, o tipo de sombreamento e a redução apresentada no FC.

Tabela 9 - Resumo dos resultados obtidos a partir dos experimentos

\begin{tabular}{c|c|c|c|c}
\cline { 2 - 4 } & Período & Data com sombreamento & Data sem sombreamento & Redução FC (\%) \\
\hline \multirow{2}{*}{$\begin{array}{c}\text { Sombreamento } \\
\text { estático }\end{array}$} & $9 \mathrm{~h} 30$ às 18h & $18 / 09 / 2018$ & $21 / 09 / 2018$ & 2,35 \\
\cline { 2 - 5 } & $12 \mathrm{~h} 30$ às $14 \mathrm{~h} 30$ & $08 / 10 / 2018$ & $06 / 10 / 2018$ & 1,17 \\
\hline \multirow{2}{*}{$\begin{array}{c}\text { Sombreamento } \\
\text { dinâmico }\end{array}$} & $13 \mathrm{~h}$ às $15 \mathrm{~h}$ & $26 / 09 / 2018$ & $21 / 09 / 2018$ & 0,84 \\
\cline { 2 - 5 } & $10 \mathrm{~h} 30$ às $12 \mathrm{~h} 30$ & $27 / 09 / 2018$ & $02 / 10 / 2018$ & 1,72 \\
\hline
\end{tabular}

Fonte: Elaborado pelos autores, 2018.

\section{Conclusão}

Neste artigo foi estudado o impacto do efeito do sombreamento na geração FV para uma planta conectada à rede na cidade de Fortaleza, CE. O sombreamento é um dos fatores que afetam o desempenho de um sistema FV, principalmente em áreas urbanas. Outros fatores, tais como maresia, sujidade e temperatura, também afetam.

O diferencial do presente estudo é não se basear em simulações computacionais em condições padrões de teste (STC), com traçadores de curvas PV e IOV e/ou com painéis/strings de referência. A microgeração FV, operando em condições reais de conexão à rede, conferiu grande credibilidade ao presente estudo. Foram desenvolvidos quatro experimentos, dois envolvendo sombreamento estático e dois envolvendo sombreamento dinâmico.

Apenas um experimento utilizou o período de um dia completo, devido à dificuldade em obter comportamento de irradiação diária semelhante para o período da manhã nos meses do segundo semestre em Fortaleza-CE, como justificado teoricamente pela literatura. Com a garantia de que o período analisado possuía irradiação semelhante, as curvas de potência foram comparadas com os dias com e sem sombreamento, e o FC foi calculado.

Como resultado, obteve-se uma redução no FC para o sombreamento estático de 2,35\% (dia 18/09/2018) e 1,17\% (dia 08/10/2018). Os valores calculados para redução no FC para o sombreamento dinâmico foram de $0,84 \%$ (dia 26/09/2018) e 1,72\% (dia 27/09/2018). Observou-se o gráfico de potência e irradiância, visto 
que a potência gerada depende da quantidade de luz incidida sobre as placas FV. O pico de geração da planta FV em estudo, para os meses analisados, se concentrou próximo às $11 \mathrm{~h}$.

Concluiu-se que, para baixas irradiâncias (inferiores a $500 \mathrm{~W} / \mathrm{m}^{2}$ ), o sombreamento não interferiu de modo significativo na potência gerada, fato que concorda com a literatura consultada. Verificou-se a atuação do diodo by-pass, que evitou que determinadas células sombreadas se comportassem como carga para a planta FV, impedindo a formação de hotspots (pontos quentes) diminuindo a queda brusca na potência de saída. Assim, o presente artigo apresentou uma contribuição para o uso da geração FV em relação ao conhecimento de possíveis perdas por conta do efeito do sombreamento para cidades próximas à linha do Equador, como é o caso de Fortaleza-CE.

\section{Referências}

BORGES NETO, M. R.; CARVALHO, P. Geração de energia elétrica: fundamentos. São Paulo: Érica, 2012.

CARVALHO, P. C. M. et al. Land requirement scenarios of PV plants in Brazil. Renewable Energy \& Power Quality Journal, Espanha, n. 16, apr. 2018. Disponível em: https://doi.org/10.24084/repqj16.252. Acesso em: 02 ago. 2018. Apresentado em International Conference on Renewable Energies and Power Quality, Salamaca, 2018.

COUTINHO, C. R. et al. Efeito do sombreamento em módulos fotovoltaicos. In: CONGRESSO BRASILEIRO DE ENERGIA SOLAR, 6., 2016, Belo Horizonte. Anais [...]. Belo Horizonte: UFMG, 2016. Disponível em: http://www.abens.org.br/CBENS2016/anais/anais/trabalhos/2594Pfinal.pdf. Acesso em: 20 set. 2018.

CHAVES, Matheus de Paula. Estudo sobre sombreamento em planta fotovoltaica localizada em zona urbana de Fortaleza-CE. 2018. Trabalho de Conclusão de Curso (Graduação em Engenharia Elétrica) Universidade Federal do Ceará, Centro de Tecnologia, Curso de Engenharia Elétrica, Fortaleza, 2018.

EMPRESA DE PESQUISA ENERGÉTICA. Balanço Energético Nacional (BEN) 2018: Ano Base 2017. Rio de Janeiro: EPE, 2018.

Disponível em: http://www.ben.epe.gov.br. Acesso em: 20 set. 2018.

GOOGLE. Google Imagens. Sombreamento em painéis fotovoltaicos. 2018. Disponível em:https://www. google.com/search?q=sombreamento+paineis+fotovoltaicos\&source=Inms\&tbm=isch. Acesso em: 02 ago. 2018.

INTERNATIONAL ENERGY AGENCY. Key World Statistics 2018. Disponível em: https://webstore.iea.org/ key-worldenergy-statistics-2018. Acesso em: 20 set. 2018.

PICANÇO, J.; ROLIM, J.; PONTE, I. Panorama mundial e brasileiro das energias renováveis. Fortaleza: CINASE, 2018.

PINHO, J. T.; GALDINO, M. A. Manual de engenharia para sistemas fotovoltaicos. Rio de Janeiro: LTC, 2014. v. 1.

PLANCHON, O. et al. A method of identifying and locating sea-breeze fronts in north-eastern Brazil by remote sensing. Meteorological Applications, Chichester, v. 13, n. 3, p. 225-234, 2006.

RABELO, A. D. S. Estudo sobre sujidade em planta fotovoltaica localizada em zona urbana. 2017. Trabalho de conclusão de curso (Graduação Engenharia Elétrica) - Universidade Federal do Ceará, Centro de Tecnologia, 2017.

RODRIGUES, M. S.; TELES, M. B.; MACÊDO, W. N. Resultados experimentais de sombreamento parcial 
em módulos fotovoltaicos. In: CONGRESSO BRASILEIRO DE ENERGIA SOLAR, 7., 2018, Gramado.

Anais [...]. Gramado: Associação Brasileira de Energia Solar, 2018. Disponível em: https://anaiscbens. emnuvens.com.br/cbens/article/view/21. Acesso em: 02 ago. 2018.

TEIXEIRA, R. F. B. O fenômeno da brisa e sua relação com a chuva sobre Fortaleza-CE. Revista Brasileira de Meteorologia, São José dos Campos, v. 23, n. 3, p. 282-291, 2008.

TEO, J. et al. Impact of partial shading on the PV characteristics and the maximum power of a photovoltaic string. Energies, Basel, v. 11, n. 7, p. 1860, 2018.

YINGLI SOLAR. Installation and user manual. p. datasheet, 2017. Disponível em: http://www.yinglisolar. com/static/assets/uploads/manual/downloads/InstallationManual_IEC_EN_20170727_V03.pdf. Acesso em: 13 set. 2018.

\section{Agradecimentos}

Paulo C. M. Carvalho agradece ao CNPq pela bolsa de pesquisador concedida; Ivonne M. Dupont e Danielly Norberto Araújo agradecem à CAPES pelas bolsas de doutorado e mestrado, respectivamente. Os autores agradecem à UFC pela disponibilidade de laboratórios e equipamentos.

Sobre os autores

\section{Matheus de Paula Chaves}

Possui graduação em Engenharia Elétrica pela Universidade Federal do Ceará (UFC). Tem experiência na área de Engenharia Elétrica, com ênfase em Controle de Processos Eletrônicos, Retroalimentação. Ao longo do curso de Engenharia Elétrica desenvolveu sistemas em Python/Java, projetou robô autônomo seguidor de linha, projetou comunicador hexadecimal utilizando microcontrolador PIC 16F628A (em Assembly), projetou software interativo com VGA em linguagem VHDL, atuou no desenvolvimento de placas de circuito impresso, desenvolveu softwares em C++ para o microcontrolador ARM Cortex M0, estudou redes de computadores (equipamentos, topologias e protocolos), projeto de instalações elétricas prediais e residenciais (utilizando Autocad, pacote office).

\section{Ivonne Montero Dupont}

Possui graduação em Engenharia da Computação na "Universidade Tecnológica da Habana José Antonio Echeverría" (2014), Habana, Cuba. Trabalhou como Especialista em Ciência da Computação desde 2006 atè 2015 na Empresa de Telecomunicações de Cuba. Tem experiência na área de monitoramento e programação em várias linguagens (C, Java, PHP, Python), também na área de administração de aplicações informáticas (SAP), administração de bancos de dados (PostgreSQL, MySQL, Oracle) e redes de computadores. Tem experiência em administração de serviços em Windows e Linux. Atualmente é aluna de doutorado do Programa de Pós-Graduação em Engenharia Elétrica da Universidade Federal do Ceará, Brasil, na área de Sistemas Linux Embarcados aplicados à Energias Renováveis.

\section{Paulo Cesar Marques de Carvalho}

Possui graduação em Engenharia Elétrica pela Universidade Federal do Ceará (1989), mestrado em Engenharia Elétrica pela Universidade Federal da Paraíba (1992) e doutorado em Engenharia Elétrica pela Universidade de Paderborn, Alemanha (1997). Atualmente é professor titular do Departamento de Engenharia Elétrica da Universidade Federal do Ceará. Tem atividades de ensino, pesquisa e extensão nos temas: geração fotovoltaica, geração eólica e biodigestores. Coordena o Laboratório de Energias Alternativas da UFC. Bolsista de produtividade em pesquisa do CNPq.

\section{Danielly Norberto Araujo}

Técnica em Eletrotécnica (2012) pelo Instituto Federal do Ceará (IFCE) e graduada em Engenheira Elétrica (2017), com ênfase em eletrotécnica, pela Universidade Federal de Campina Grande (UFCG). Atualmente, é mestranda no Programa de Pós-Graduação em Engenharia Elétrica da Universidade Federal do Ceará (UFC), na área de sistemas elétricos de potência. Seus interesses são: geração distribuída, geração solar fotovoltaica e sistemas de armazenamento de energia.

Recebido em: 18.01.2019

Aceito em: 12.03.2019 